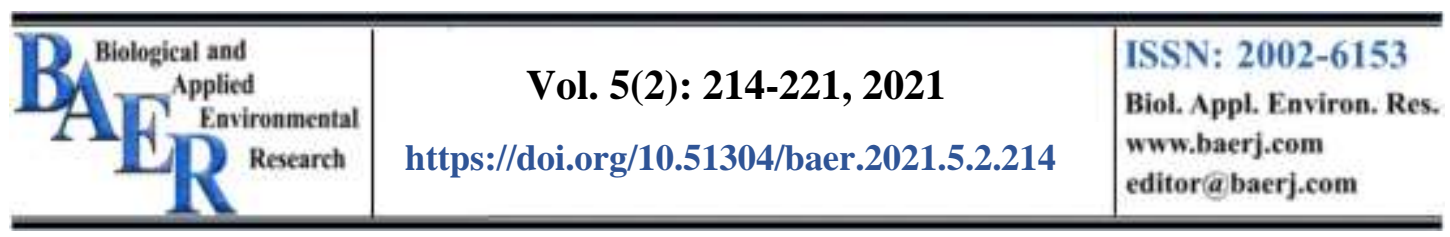

\title{
Grading Effects on Growth and Size Variation of Common Carp Cyprinus carpio Cultivated in Floating Cages
}

\author{
Rahman H.T. Albahadly ${ }^{1}$, Adel Y. Al-Dubakel ${ }^{2 *}$ \& Majid M. Taher ${ }^{2}$ \\ ${ }^{1}$ Maysan Agriculture Directorate, Ministry of Agriculture, Iraq \\ ${ }^{2}$ Aquaculture Unit, College of Agriculture, University of Basrah, Basrah, Iraq \\ *Corresponding author: aaldubakel22@gmail.com
}

\begin{abstract}
The present study aimed to investigate the effect of fish grading on the growth performance of common carp Cyprinus carpio cultivated in floating cages located in the Al-Mashab River northwest of Basrah. A total of 4896 fishes were transferred from storage cages to culture cages $(3 \times 4 \times 2 \mathrm{~m})$, and distributed at a rate of 816 fishes per cage with a culture density of 34 fishes $/ \mathrm{m}^{3}$ into six cages, three of which were classified into large (GL), middle (GM) and small (GS) individuals, whereas three cages were left without grading (UG). The graded and ungraded cages were chosen depending on the standard deviation for each cage. The fishes were fed for both treatments on a standardized, locally made diet. The results of the study were evaluated according to the criteria for total weight gain (WG), daily growth rate and specific growth rate. In the first grading process, significant differences $(\mathrm{P}<0.05)$ were recorded between graded $(\mathrm{GL})$ and ungraded in final weight and specific growth rate (SGR) but not in weight gain and daily growth rate (DGR), while in the second grading, significant differences $(\mathrm{P}<0.05)$ were recorded between graded (GL) and ungraded in final weight and weight gain but not in SGR and DGR. At the end of the second grading period, the daily and specific growth rate of graded fishes were ranged between 3.26-4.73 g/day and 0.22$0.46 \% /$ day, respectively, while for ungraded fishes there were $2.35 \mathrm{~g} /$ day and $0.23 \% /$ day, respectively. The survival rate (SR) was not different very much in all treatments and ranged between 94.34 to $95.49 \%$ in small graded and ungraded fishes, respectively. The study results recommend at least two grading processes should be established during the culture season in two or three months intervals.
\end{abstract}

Keywords: Sorting, SGR, DGR, Common carp, Size distribution

\section{Introduction}

The best modern technology achieved in the last twenty years in the field of aquaculture is the technique of cage aquaculture, which is relatively new to the inland aquaculture development of many countries that offer new prospects for enhancing fish production, and also emerging new skills among fishermen and to enhance their incomes (NFDB, 2016). This technology was used since earlier 
periods, but the development and modifications made to the designs and materials of cages, the methods of construction and operation, and the great progress in processed diets, all those have led to the spread of this technology on a large scale in many countries around the world (Pillay \& Kutty, 2005). The techniques used in the growth and production of fishes in cages were relatively new in Asia, although the origins of using cages to transport and preserve fishes for not long periods date back nearly two centuries and the great development of intensive culture systems in cages was driven by several factors, including the competition of this system.

Differences in individual growth rate within a fish population are common and cause a major impediment to cost-effective management in commercial fish culture (Benhaïm et al., 2011). The size of fish changes is due to the individual growth, and thus the fishes reach at the end of the cultivation season different heterogeneous sizes, so it usually requires sorting for those fishes that have reached the marketable size from those that are below the required weights which returned back to the culture system until they reach the appropriate size for marketing. So, reducing the unevenness in size and increasing the homogeneity of weight are important goals in the culture of fishes (Kim et al., 2020). The grading process takes place during the cultivation season at different intervals according to the change in the size of the fishes during sorting and sampling. The process of sorting and grading may take long times, skilled labor and great effort. Among the benefits of grading is the classification of fishes according to size and display to the consumer and that fish producer can display fishes in several sizes (Kelly \& Heikes, 2013). Other benefits of grading include the elimination of the phenomenon of competition for food, especially in cages. This phenomenon results in great different sizes of fishes. Large fishes consume more feed and do not give an opportunity to allowing smaller fishes to take their adequate food. When graded, this phenomenon will be eliminated. Among the other benefits of grading is the reduction of the phenomenon of cannibalism, in other words, larger fishes eat smaller ones (Heikes, 2007). Grading by size should reduce the stress imposed by the larger individuals over small individuals (Hirt-Chabbert et al., 2014).

Coulibaly et al. (2007) demonstrated that when the process of grading or approximating the size of the cultured fishes was carried out due to the reduction of the phenomenon of competition and predation, the survival and growth rate of African catfish Heterobranchus longifilis raised in floating cages with different culture densities increased when the process of grading or approximation of the size of the cultured fishes was carried out due to the reduction of the phenomenon of competition and predation. Size grading is thought to reduce the harmful effects on small fishes, resulting in a reduction in size dissimilarity and improved biomass gain (Barki et al., 2000). Sometimes, size-grading of immature fishes is used as a tool to increase production through selection for fast-growing fishes and to minimize growth variability (Lima, 2020).

The present study aims to demonstrate the importance of common carp (Cyprinus carpio) grading in floating cages and its effect on growth and size variation. 


\section{Materials and Methods}

\section{Cages and Stoking Density}

The research study was implemented in Al-Ahwar Company for Fish Production and Marketing in Al-Mashab, northwest of Basrah $\left(30^{\circ} 62^{\prime} 96.9^{\prime \prime} \mathrm{N}, 47^{\circ} 66^{\prime} 85.5^{\prime \prime} \mathrm{E}\right)$. Six cages $(3 \times 4 \times 2 \mathrm{~m})$ were selected and common carps, obtained from the same company, were sorted and isolated from other fishes in special cages. Care was taken in preparation for transporting them to the experimental culture cages. The cages were covered with special cover nets to prevent the fishes from escaping into the natural waters.

After completing the preparation of the culture cages (ensure that the wooden frames of the cages are not damaged, passages of the main cages are free from damage, the safety of the cages buoyancy materials and be free from corrosion and breakage, checking the depths under the cages, which must not be less than $2 \mathrm{~m}$ in the lowest tide, make sure that the location of the cages is free of rodents, which causes rupture of nets, escape of fish, and damage to buoyancy materials), a total of 4896 common carps $(542.38 \pm 29.17 \mathrm{~g})$ were transferred from the storage cages to six culture cages. A total of 816 fishes were distributed per cage at a culture density of 34 fishes $/ \mathrm{m}^{3}$. During the process of transferring the fishes from the storage cages to the experimental cages, the fishes were sterilized with a solution of copper sulfate at a concentration of $0.10 \%$ for a period of 25 seconds in order to eliminate various pathogens. The fishes were left for 48 hours to empty their digestive tracts from the previous feed. About 80 fishes were randomly sampled by a hand-net from each of the six cages and the live fishes were weighed to the nearest $0.5 \mathrm{~g}$ in each sampling.

\section{Feed and Feeding}

Local feeds (Table 1) were used to feed the fishes, which were made in the feed manufacturing plant at the Marine Science Centre, University of Basrah. The feeding rate was $5 \%$ of body weight and $3 \%$ during a limited period (one month) due to high temperatures and low food intake according to daily observations, at a rate of two meals; in the morning and in the afternoon. The weighing process was repeated for specific intervals between weighing until the end of the experiment, in order to adjust the amount of the daily food given according to the new weights.

Table 1: Ingredients and proximate composition of the experimental diets.

\begin{tabular}{|l|c|c|c|}
\hline \multicolumn{1}{|c|}{ Ingredients } & $\%$ & \multicolumn{2}{c|}{ Chemical analysis (\%) as DM } \\
\hline Fish meal & 25 & Moisture & 3.49 \\
\hline Wheat flour & 35 & Crud protein & 33.08 \\
\hline Wheat bran & 30 & Crud lipid & 5.93 \\
\hline Yellow corn & 10 & Ash & 8.57 \\
\hline \multicolumn{2}{|r}{} \\
\hline
\end{tabular}




\section{Sampling and Grading}

After two months, the fishes were weighed in the six cages. Three cages were determined to be graded, based on the standard deviation (cages with high standard deviation) and according to fish size into a large (GL), medium (GM) and small (GS) grading, while the other three cages were left without grading (UG). The first grading process was carried out during this period, while the second grading process was carried out for the three cages after three months from the first grading. During the experiment, the average weight of each cage before and after the grading process was measured. At the end of the experiment, after 170 days, all the six graded and ungraded cage fishes were weighed and counted.

\section{Measuring Water Quality}

During the experimental periods, the surface water temperature in each sample was measured by using a simple thermometer.

\section{Measuring Growth Performance}

The following equations were used to describe the growth performance of the brood stock:

Weight Gain $(\mathrm{WG})=\mathrm{W} 2(\mathrm{~g} /$ fish $)-\mathrm{W} 1(\mathrm{~g} /$ fish $)$

Daily Growth Rate (DGR) = (W2 g/fish - W1 g/fish)

$(\ln W 2 \mathrm{~g} /$ fish $-\ln W 1 \mathrm{~g} /$ fish $)$

Specific Growth Rate (SGR) = ---

Where $\ln W 2$ is the natural logarithm of the final weight at the time $\mathrm{T} 2, \ln \mathrm{W} 1$ is the natural logarithm of the initial weight at the time T1 and T2-T1 is the period between the two weights.

$$
\begin{aligned}
& \text { Number of fish alive } \\
& \text { Survival Rate (SR) = ------------------------------- X } 100
\end{aligned}
$$

\section{Statistical Analysis}

All parameters were tested by using a one-way analysis of variance (ANOVA). Significant results $(\mathrm{P}<0.05)$ were tested by using LSD to the test significant difference between means. This statistical analysis was completed with the computer software SPSS package Version 22.

\section{Results}

Water temperature ranged between $21.6{ }^{\circ} \mathrm{C}$ in November and $31.3{ }^{\circ} \mathrm{C}$ in June (the average was $26.6^{\circ} \mathrm{C}$ ). The mean total weight gain of the graded and ungraded fishes after two months was shown in Table 2 . The average weight gain in the first 
grading process was ranged between 65.30 and $188.40 \mathrm{~g}$ for three size graded fishes, while the ungraded fishes recorded $205.53 \mathrm{~g}$. Significant differences $(\mathrm{P}<0.05)$ were recorded between graded and ungraded fishes in final weight and SGR but not in both weight gain and DGR. In the second grading process, the weight gain rate of graded fishes ranged between 248.00 and 359.10 versus 178.43 $\mathrm{g}$ for ungraded ones (Table 3). Significant differences $(\mathrm{P}<0.05)$ were recorded between graded and ungraded fishes in final weight and weight gain but not in both SGR and DGR. The results showed that the daily and specific growth rates for both graded and ungraded fishes at the end of the first grading period were ranged between 2.18 and $6.28 \mathrm{~g} /$ day and from 0.27 to $0.66 \% /$ day for graded fishes, respectively, while for ungraded fishes, they were $2.28 \mathrm{~g} /$ day and $0.27 \% /$ day, respectively. At the end of the second grading period, the daily and specific growth rates of graded fishes ranged between $3.26-4.73 \mathrm{~g} / \mathrm{day}$ and $0.22-0.46 \% /$ day, respectively. For ungraded fishes, they were $2.35 \mathrm{~g} /$ day and $0.23 \% / d a y$, respectively. The survival rate was not different very much in all treatments and ranged between 94.34 and $95.49 \%$ in small graded and ungraded fishes, respectively.

Table 2: Growth parameters of common carps in graded and ungraded cages in the first period (two months) (Mean \pm SD).

\begin{tabular}{|l|c|c|c|c|}
\hline \multirow{2}{*}{ Parameters } & \multicolumn{4}{|c|}{ Treatments (first period) } \\
\cline { 2 - 5 } & Ungraded (UG) & Graded (GL) & Graded (GM) & Graded (GS) \\
\hline IW $(\mathrm{g})$ & $731.8^{\mathrm{b}} \pm 53.46$ & $1014.7^{\mathrm{a}} \pm 138.0$ & $740.1^{\mathrm{b}} \pm 57.8$ & $537.6^{\mathrm{c}} \pm 61.9$ \\
\hline FW (g) & $937.3^{\mathrm{b}} \pm 53.46$ & $1203.1^{\mathrm{a}} \pm 121.2$ & $805.4^{\mathrm{b}} \pm 93.1$ & $655.7^{\mathrm{c}} \pm 74.5$ \\
\hline WG $(\mathrm{g})$ & $205.53^{\mathrm{a}} \pm 11.21$ & $188.40^{\mathrm{a}} \pm 16.80$ & $65.30^{\mathrm{b}} \pm 35.30$ & $118.10^{\mathrm{c}} \pm 12.60$ \\
\hline DGR (g/day) & $6.85^{\mathrm{a}} \pm 0.37$ & $6.28^{\mathrm{a}} \pm 0.56$ & $2.18^{\mathrm{b}} \pm 1.18$ & $3.94^{\mathrm{c}} \pm 0.42$ \\
\hline SGR (\%/day) & $0.83^{\mathrm{a}} \pm 0.09$ & $0.58^{\mathrm{b}} \pm 0.12$ & $0.27^{\mathrm{c}} \pm 0.13$ & $0.66^{\mathrm{ab}} \pm 0.01$ \\
\hline
\end{tabular}

Data with different superscripts are significantly different $(\mathrm{P}<0.05)$.

Table 3: Growth parameters of common carps in graded and ungraded cages in the second period (three months) (Mean $\pm \mathrm{SD})$.

\begin{tabular}{|l|c|c|c|c|}
\hline \multirow{2}{*}{ Parameters } & \multicolumn{4}{|c|}{ Treatments (second period) } \\
\cline { 2 - 5 } & Ungraded (UG) & Graded (GL) & Graded (GM) & Graded (GS) \\
\hline IW (g) & $937.3^{\mathrm{b}} \pm 53.46$ & $1330.4^{\mathrm{a}} \pm 65.5$ & $851.3^{\mathrm{bc}} \pm 28.2$ & $762.2^{\mathrm{c}} \pm 60.7$ \\
\hline FW (g) & $1115.7^{\mathrm{bc}} \pm 13.6$ & $1578.4^{\mathrm{a}} \pm 124.5$ & $1210.4^{\mathrm{b}} \pm 66.6$ & $1064^{\mathrm{c}} \pm 81.7$ \\
\hline WG (g) & $178.43^{\mathrm{c}} \pm 29.67$ & $248.00^{\mathrm{b}} \pm 59.00$ & $359.10^{\mathrm{a}} \pm 38.40$ & $301.80^{\mathrm{a}} \pm 21.00$ \\
\hline DGR (g/day) & $2.35^{\mathrm{b}} \pm 0.40$ & $3.26^{\mathrm{b}} \pm 0.78$ & $4.73^{\mathrm{a}} \pm 0.51$ & $3.97^{\mathrm{a}} \pm 0.28$ \\
\hline SGR (\%/day) & $0.23^{\mathrm{b}} \pm 0.04$ & $0.22^{\mathrm{b}} \pm 0.04$ & $0.46^{\mathrm{a}} \pm 0.03$ & $0.44^{\mathrm{a}} \pm 0.00$ \\
\hline Survival (\%) & 95.49 & 94.58 & 95.43 & 94.34 \\
\hline
\end{tabular}

Data with different superscripts are significantly different $(\mathrm{P}<0.05)$.

Size distribution of common carps in graded and ungraded cages, as revealed in Table 4, showed that about $60 \%$ of ungraded fishes were under $1000 \mathrm{~g}$, while about $70 \%$ of graded fishes were above $1000 \mathrm{~g}$. Only two compared to five fishes reached more than $2000 \mathrm{~g}$ in both groups, respectively. 
Table 4: Size distribution of common carps in graded and ungraded cages.

\begin{tabular}{|l|c|c|c|c|}
\hline \multirow{2}{*}{ Weight range (g) } & \multicolumn{4}{|c|}{ Treatments } \\
\cline { 2 - 5 } & \multicolumn{2}{|c|}{ Ungraded (UG) } & \multicolumn{2}{c|}{ Graded (G) } \\
\cline { 2 - 5 } & No. & $\%$ & No. & $\%$ \\
\hline $300-599$ & 205 & 8.61 & 0 & 0 \\
\hline $600-999$ & 1209 & 50.76 & 737 & 51.23 \\
\hline $1000-1499$ & 895 & 37.57 & 1241 & 15.98 \\
\hline $1500-2009$ & 71 & 2.99 & 377 & 0.21 \\
\hline $2010-2499$ & 2 & 0.07 & 5 & 100 \\
\hline Total & 2382 & 100 & 2360 & \\
\hline
\end{tabular}

\section{Discussion}

Under the concept of commercial fish farming, there are several steps involved, including sorting and classifying live fishes or what is called grading, which is an important step in commercial farming that allows producers to benefit from the maximum profit of the project since the price of fishes varies according to their size, especially in local markets. Also, mixing large and small fishes gives an undesirable appearance product to the retail seller that sells fishes to the consumer.

Through the results of the daily growth rate, it is noted that the great importance of the grading process, as the fish that had a grading process, their daily growth rates were comparable due to the uniformity of their weights, which reduced the phenomenon of competition for the feeds provided and thus converted these feeds consumed into daily growth among the graded fishes. Due to the variation in size, ungraded fishes showed lower daily growth rates as a result of intense competition for feed between small and large-size fishes, especially at the second grading process. Table 4 demonstrated the consequence of large fishes on the growth of smaller ones in the ungraded cages.

The results of the current experiment are in agreement with those of Al-Rudainy et al. (1999) when they cultivated different sizes of common carps in earthen ponds and found that the best growth was in the treatment of closely related fishes (graded) and their daily growth rate was $2.8 \mathrm{~g} / \mathrm{day}$, while the daily growth of different fish weights (ungraded) was $1.5 \mathrm{~g} / \mathrm{day}$. The low daily growth rate of ungraded fishes may be due to small individuals which contribute about $60 \%$ from the total size range below 1000g. Abu-elheni et al. (2015) indicated that the best daily growth of common carps cultured in floating cages was in the similar weights and achieved daily growth of 6.74 and $6.62 \mathrm{~g} /$ day, respectively, while the daily growth rate of the control treatment, which contained different sizes of fishes, was $2.48 \mathrm{~g} /$ day.

Castillo-Vargasmachnca et al. (2007) found the best growth rate for the spotted rose snapper (Lutjanus guttatus), cultured in floating cages of three different sizes, was in the treatment of larger fishes $(110.2 \mathrm{~g})$. In other words, the cages that contained high weights with little variations, are consistent with the results of the current experiment. 
The results of the present experiment were not consistent with that of Akbulut et al. (2002) who found the best daily growth rate in the treatment of small-sized fishes when culturing rainbow trout (Oncorhynchus mykiss) in three different sizes (small, medium and large size) of floating cages. The best growth rate was in the treatment of smaller size, while the results of the current study showed that the best growth was in the treatment of fishes in large-sized fishes. The same researchers found that similar size fishes outperformed the specific growth rate $(1.11 \% /$ day $)$ over the other treatments $(1.02 \% /$ day), whose sizes were different, which were consistent with the results of the current experiment.

Partial harvesting has been earlier known in some cases (Brummett, 2002; Yu \& Leung, 2006), but are not practical for applications in the present study, mostly due to an increase in the production costs and in succession consumers and sellers favor large common carps (more than $1500 \mathrm{~g}$ ). Previous studies assumed that fish's heterogeneity is related to differences in initial sizes, but Kim et al. (2020) suggested that it is a difficult factor to control and heterogeneity in the size of fishes of the same age appears to be as a natural phenomenon.

\section{Conclusions}

The current study showed the importance of fish grading, especially in cages, and its effect on growth and size variations, which will affect the production and profit of the culture project. At least two grading processes should be established during the culture season in two or three month's intervals when initial fish weight ranged between $250-500 \mathrm{~g}$.

\section{Acknowledgements}

The researchers thank the employees of the Al-Ahwar Company for Fish Production and Marketing for their efforts and assistance during the culture and sampling of fishes as well as for providing efforts to accomplish this experiment.

\section{References}

Abu-elheni, A.-K.J.; Abbas, L.M. \& Wahab, N.K. (2015). Effect of stocking density and segmentation of rearing period on the growth and survival rate of common carp Cyprinus carpio L. in floating cages. Iraqi J. Sci. Tech., 6(2): 44-52. (In Arabic).

Akbulut, B.; Şahin, T.; Aksungur, N. \& Aksungur, M. (2002). Effect of initial size on growth rate of rainbow trout, Oncorhynchus mykiss, reared in cages on the Turkish Black Sea coast. Turkish J. Fish. Aquat. Sci.., 2(2): 133-136.

Al-Rudainy, A.J.; Salman, N.A.; Ruhaige, A.M.; Abo Al-Hani, A.J. \& Mosa, K.M. (1999). Effect of multi-size culture on the growth, food conversion and production of common carp Cyprinus carpio L. J. Iraqi Atomic Energy Comm., 1(1): 128-145. (In Arabic).

Barki, A.; Harpaz, S.; Hulata, G. \& Karplus, I. (2000). Effects of larger fish and size grading on growth and size variation in fingerling silver perch. Aquac. Int., 8(5): 391-401. DOI:10.1023/A:1009274726380. 
Benhaïm, D.; Péan, S.; Brisset, B.; Leguay, D.; Bégout, M.-L. \& Chatain, B. (2011). Effect of size grading on sea bass (Dicentrarchus labrax) juvenile self-feeding behaviour, social structure and culture performance. Aquat. Living Resour., 24, 391-402. DOI:10.1051/alr/2011140.

Brummett, R.E. (2002). Comparison of African tilapia partial harvesting systems. Aquaculture, 214(1-4): 103-114. DOI:10.1016/S0044-8486(01)00850-X.

Castillo-Vargasmachnca, S.; Ponce-Palafox, J.T.; Chávez Ortíz, E. \& ArredondoFigueroa, J.L. (2007). Effect of the initial stocking body weight on growth of spotted rose snapper Lutjanus guttatus (Steindachner, 1869) in marine floating cages. Rev. Biol. Mar. Oceanogr., 42(3): 261- 267.

Coulibaly, A.; Ouattara, I.N.; Koné, T.; N'Douba, V.; Snoeks, J.; Gooré, Bi. \& Kouamélan, E.P. (2007). First result of floating cage culture of the African catfish Heterobranchus longifilis Valenciennes, 1840: Effect of stocking density on survival and growth rates. Aquaculture, 263: 61-67.

Heikes, D. (2007). Components and use of an in-pond fish grading system. South. Reg. Aquac. Cent. Publ. No. 3901: 5 pp.

Hirt-Chabbert, J.A.; Sabetian, A. \& Young, O.A. (2014). Effect of size grading on the growth performance of shortfin eel (Anguilla australis) during its yellow stage. N. Z. J. Mar. Freshw. Res., 48(3): 385-393. DOI:10.1080/ 00288330.2014 .924538$.

Kelly, A.M. \& Heikes, D. (2013). Sorting and grading warmwater fish. South. Reg. Aquac. Cent. Publ. No. 391: 8 pp.

Kim, P.B.; Klanian, M.G. \& Seijo, J.C. (2020). Effect of size heterogeneity of Nile tilapia (Oreochromis niloticus) on the optimal harvest time: A bioeconomics approach. Lat. Am. J. Aquat. Res., 48(1): 65-73. DOI:10.3856/vol48-issue1fulltext-2360.

Lima, A.F. (2020). Effect of size grading on the growth of pirarucu Arapaima gigas reared in earthen ponds. Lat. Am. J. Aquat. Res., 48(1): 38-46. DOI:10.3856/ vol48-issue1-fulltext-2334.

NFDB (National Fisheries Development Board) (2016). Guidelines for cage culture in inland open water bodies of India. Dept. Anim. Husb., Dairying Fish., New Delhi: 14 pp.

Pillay, T.V.R. \& Kutty, M.N. (2005). Aquaculture: Principles and practices, $2^{\text {nd }}$ edition. Blackwell Publ., Oxford: 640 pp.

Yu, R. \& Leung, P. (2006). Optimal partial harvesting schedule for aquaculture operations. Mar. Resour. Econ., 21(3): 301-315. DOI:10.1086/ mre.21.4.42629526. 